\title{
THE PERFORMANCE OF EXPLICIT FORMULAS FOR DETERMINING THE DARCY- WEISBACH FRICTION FACTOR
}

\author{
Renata T. de A. Minhoni ${ }^{*}$, Francisca F. S. Pereira ${ }^{1}$, Tatiane B. G. da Silva ${ }^{1}$, \\ Evanize R. Castro ${ }^{1}$, João C. C. Saad ${ }^{1}$ \\ ${ }^{1 *}$ Corresponding author. São Paulo State University/ Botucatu - SP, Brazil. \\ E-mail: renataminhoni@hotmail.com | ORCID ID: http://orcid.org/0000-0002-8040-8852
}

\section{KEYWORDS}

absolute roughness, Colebrook equation, forced conduits, head loss, hydraulic load, Reynolds number.

\begin{abstract}
The Darcy-Weisbach equation is the most recommended equation for determining the pressure loss in pressurized pipes because of its wide applicability. However, one of the largest obstacles to implementing this equation is the friction factor $(f)$ calculation. This factor can be precisely determined using the Colebrook equation, which is implicit. Thus, the objective of this study was to compare six explicit equations for calculating the DarcyWeisbach friction factor with the implicit Colebrook equation based on the relative error. Based on the results, the equations of Vatankhah and Offor \& Alabi were the most highly recommended. These six explicit formulas showed a mean relative error of less than $\pm 1 \%$ compared to the Colebrook equation, except for the Swamee and Jain equation, for which the laminar regime generated a mean relative error of $1.83 \%$.
\end{abstract}

\section{INTRODUCTION}

The main problems encountered in the flow of pressurized conduits are related to the methods of determining the diameter, flow rate or pressure loss in the pipe for a given set of known variables. According to Bardestani et al. (2017), in optimization studies and hydraulic analyses of pipelines and water distribution systems, these problems are extremely significant because they affect both the hydraulic balance and system costs. The Darcy-Weisbach equation, which is shown in [eq. (1)] and is known as the universal equation, is one of the most complete mathematical equations used to determine the pressure loss in pipes because it is related to both the characteristics of the flowing fluid and the conduit material and can be applied to any type of material and any pipe diameter.

$$
h f=f \frac{L}{D} \frac{V^{2}}{2 g}
$$

in which:

$h f$ is the head loss, m;

$L$ is the pipeline length, m;
$V$ is the average flow velocity, $\mathrm{m} \mathrm{s}^{-1}$;

$D$ is the inner pipe diameter, $\mathrm{m}$;

$g$ is the gravitational acceleration, $\mathrm{m} \mathrm{s}^{-2}$, and

$f$ is the friction factor, dimensionless.

The friction factor is dependent on the Reynolds number and the absolute roughness $(\varepsilon$, in $\mathrm{m}$ ) of the inner wall of the pipe. The main limitation preventing the wide use of the Darcy-Weisbach equation is the estimation of the friction factor $(f)$.

According to Coban (2012), the implicit Colebrook equation (1939), which is shown in equation (2), provides the best approximation of the friction factor, especially for a turbulent flow regime. This equation relates the Reynolds number $(\mathrm{R})$ and the relative roughness of the pipe $(\varepsilon / D)$ (Brkić \& Ćojbašić, 2017). The work of Colebrook \& White (1937) is often cited as the source of the equation; however, the Colebrook equation was developed by Colebrook (1939) (Vatankhah 2018; Fang, Xu \& Zhou 2011).

Several explicit friction factor approximations have been developed to replace Colebrook's implicit standard equation; the most cited are the Moody (1947), Jain

\footnotetext{
${ }^{1}$ São Paulo State University/Botucatu - SP, Brazil.
} 
(1976), Swamee \& Jain (1976), Churchill (1973), Haaland (1983), Papaevangelou et al., (2010) and Fang et al., (2011) equations.

Any effort to present a simple full-range solution for the friction factor would be of practical importance. Offor \& Alabi (2016) suggested a new equation for the friction factor that focuses on precision and computational efficiency.

Vatankhah (2018) proposed analytical solutions for the Colebrook equation with a minimal number of natural logarithms and noninteger powers (lower computational cost).

According to Offor \& Alabi (2016), the search for a fast, noniterative and accurate model, as an alternative to the Colebrook equation, led to several explicit models for obtaining the friction factor. The authors asserted that these explicit models differ in their precision and relative computational efficiency, depending on the degree of complexity, and they adopted the relative error as a precision indicator.

Mikata \& Walczak (2016) stated that the goal is not to discourage the use of the Colebrook equation, which is used in many engineering projects, but rather to determine the friction factor by using explicit equations that provide results similar to the empirically correct results obtained from the Colebrook equation.

The hypothesis of this work is as follows: the implicit Colebrook equation for estimating the friction factor can be replaced with explicit formulas at less than $1 \%$ relative error. Therefore, the objective of this work was to evaluate the approximations of six explicit formulas for calculating the friction factor of the Darcy-Weisbach equation and compare them to the implicit Colebrook equation in terms of their relative error.

\section{MATERIAL AND METHODS}

For this study, among the numerous equations available in the literature to obtain the friction factor of the Darcy-Weisbach equation, six explicit formulas, as described in Table 1, were selected based on the number of citations in scientific articles on irrigation and hydraulic projects, with a preference for the most recent equations.

TABLE 1. Equations selected to determine the friction factor.

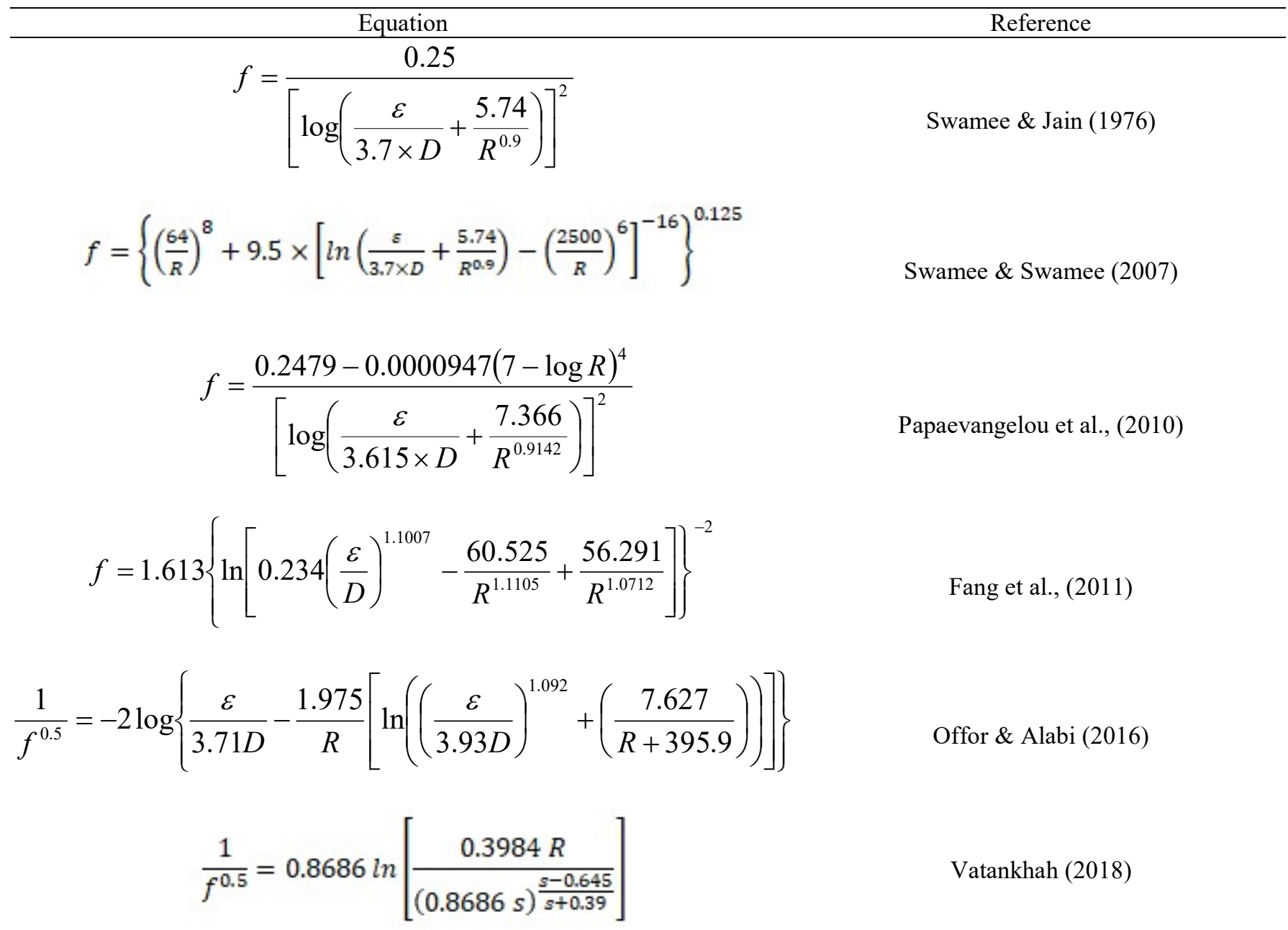

Note: $f=$ friction factor, dimensionless; $\varepsilon=$ average protrusion height of the inner pipe surface, $\mathrm{m} ; D=$ inner pipe diameter, $\mathrm{m}$;

$\mathrm{R}=$ Reynolds number, dimensionless, and $s=0.12363 R\left(\frac{\varepsilon}{D}\right)+\ln (0.3984 R)$. 
The friction factor approximations obtained via the explicit formulas were compared with the values obtained using the Colebrook equation (1939), which is an implicit equation that is used worldwide and covers the entire range of Reynolds number and relative surface roughness values, as shown in [eq. (2)].

$$
\frac{1}{f^{0.5}}=-2 \log \left[\frac{\varepsilon / D}{3.7}+\frac{2.51}{R f^{0.5}}\right]
$$

in which:

$f$ is the Darcy-Weisbach friction factor,
dimensionless; $\varepsilon / D$ is the relative surface roughness, dimensionless;

$\varepsilon$ is the average protrusion height of the inner pipe surface, m;

$D$ is the inner pipe diameter, $\mathrm{m}$, and

$\mathrm{R}$ is the Reynolds number, dimensionless.
To verify the accuracy of the friction factor approximations obtained using the explicit formulas, the relative error, as given by [eq. (3)], was calculated using the Colebrook equation result as the reference.

$$
\text { relativeerror }=\frac{f_{\text {Colebrook }}}{f_{\text {empiricalformula }}}-1
$$

Following Papaevangelou et al., (2010), R values between 4,000 and $10^{8}$, which cover the entire proposed range of the Moody (1944) diagram, were adopted. The $\varepsilon / D$ values were based on the pipe materials most often used in irrigation and hydraulic projects, which include polyvinyl chloride (PVC), linear low-density polyethylene (LLDPE), galvanized steel and aluminum. The $\varepsilon / D$ values for PVC and LLDPE were from Rocha et al. (2017), as specified in Table 2, and the values for galvanized steel $(0.0007 \mathrm{~m})$ and aluminum $(0.0010 \mathrm{~m})$ were obtained from Testezlaf (1982). Moreover, based on Moody's (1944) diagram, values of $0.000001 \mathrm{~m}, 0.000005 \mathrm{~m}$ and $0.00001 \mathrm{~m}$ were considered. The values of $\mathrm{R}$ and $\varepsilon / D$ are presented in Table 3 .

\begin{tabular}{|c|c|c|c|c|}
\hline Material & $\mathrm{DN}(\mathrm{mm})$ & $\mathrm{Di}(\mathrm{mm})$ & $\varepsilon(\mathrm{mm})$ & $\varepsilon / D$ \\
\hline \multirow{3}{*}{ PVC } & 35 & 35.71 & \multirow{3}{*}{0.003334} & 0.00009 \\
\hline & 50 & 47.56 & & 0.00007 \\
\hline & 75 & 72.05 & & 0.00005 \\
\hline \multirow{5}{*}{ LLDPE } & 10 & 9.55 & \multirow{5}{*}{0.008116} & 0.0008 \\
\hline & 13 & 13.12 & & 0.0006 \\
\hline & 16 & 16.81 & & 0.0005 \\
\hline & 20 & 20.72 & & 0.0004 \\
\hline & 26 & 27.24 & & 0.0003 \\
\hline
\end{tabular}

TABLE 2. Relative roughness $(\varepsilon / D)$ values for PVC and LLDPE pipes.

Source: Adapted from Rocha et al. (2017).

TABLE 3. Relative roughness values $(\varepsilon / D)$ and Reynolds numbers $(\mathrm{R})$ used to verify the performance of the explicit formulas.

\begin{tabular}{ccc}
\hline$\varepsilon / D$ & $\mathrm{R}$ \\
\hline 0.000001 & 4,000 \\
0.000005 & 8,000 \\
0.00001 & 10,000 \\
0.00005 & 20,000 \\
0.00007 & 40,000 \\
0.00009 & 80,000 \\
0.0001 & 100,000 \\
0.0003 & 150,000 \\
0.0004 & 200,000 \\
0.0005 & 400,000 \\
0.0006 & 800,000 \\
0.0007 & $1,000,000$ \\
0.0008 & $2,000,000$ \\
0.001 & $4,000,000$ \\
0.005 & $8,000,000$ \\
0.05 & $10,000,000$ \\
& $20,000,000$ \\
& $40,000,000$ \\
& $80,000,000$ \\
& $100,000,000$ \\
\hline
\end{tabular}


The $\mathrm{R}$ and $\varepsilon / D$ values generated 320 combinations, and for each one, the friction factor was determined using the six explicit formulas and the Colebrook equation. For this purpose, an algorithm was developed using the MATLAB R2017a software, and the sequence of commands established by Clamond (2009) was used in the Colebrook equation implementation because of its speed of convergence. The program also determined the relative error with respect to the Colebrook equation for each combination tested. Based on the generated data, the results for each explicit equation were plotted as a function of R using the Microsoft Excel 2016® software package.

\section{RESULTS AND DISCUSSION}

The relative errors of the friction factor obtained using the Swamee \& Jain equation (1976) for the 320 combinations between $\varepsilon / D$ and $\mathrm{R}$ are shown in Figure 1 . The relative error ranged from -0.0302 to 0.0071 , and for $\mathrm{R} \leq 4,000$, which is typical of the laminar regime, all $\varepsilon / D$ values exceeded a $1 \%$ relative error, similar to the findings of Papaevangelou et al., (2010), who also found a relative error of less than $1 \%$ for $\mathrm{R}>80,000$. In the present study, a relative error of less than $1 \%$ was obtained for $80,000 \leq$ $\mathrm{R} \leq 20,000,000$.

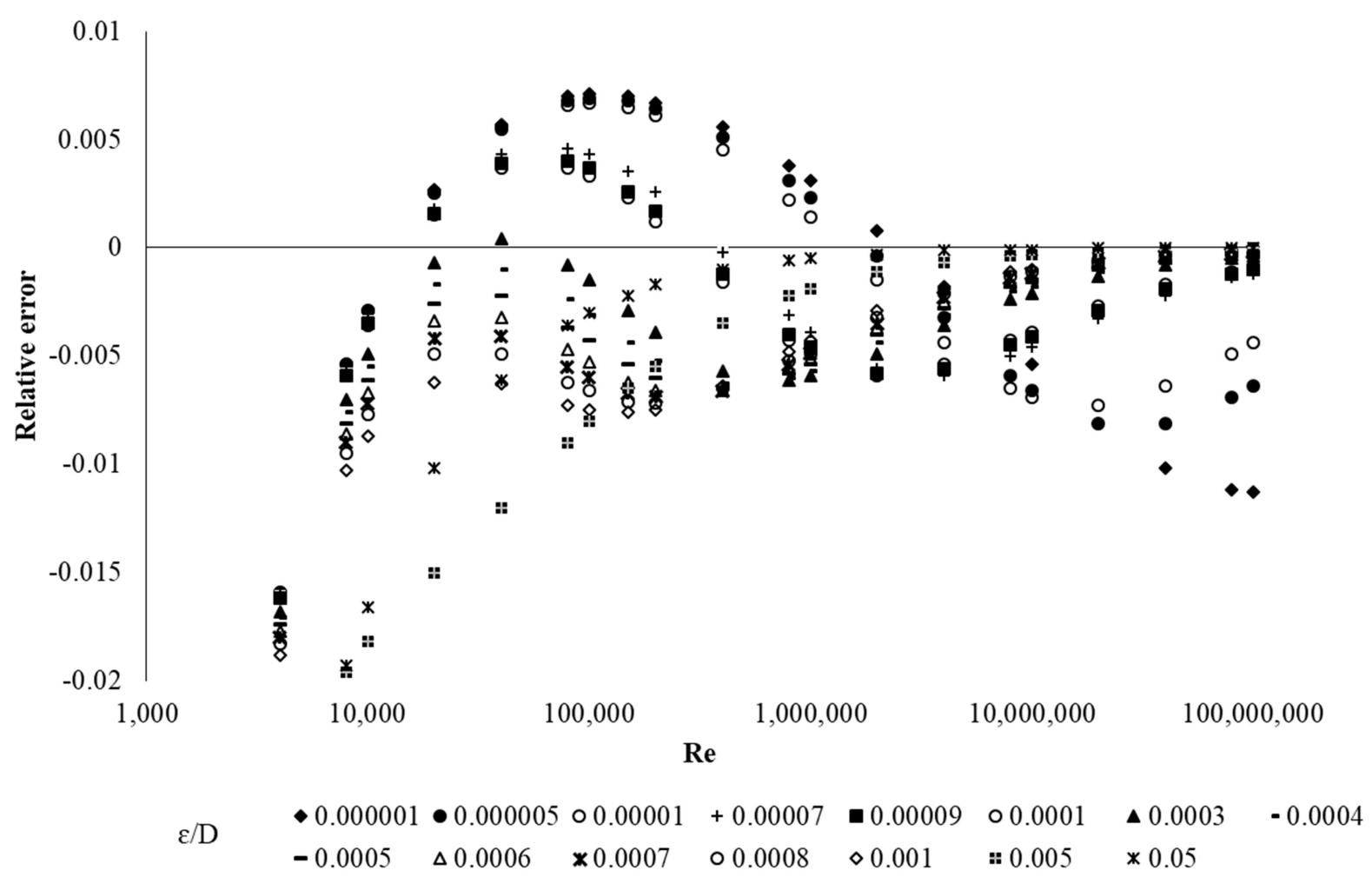

FIGURE 1. Relative error of the Swamee \& Jain equation (1976) as a function of the Reynolds number.

The Swamee \& Jain equation (1976) was proposed for the turbulent regime; thus, the largest relative errors should occur in the range corresponding to the laminar regime $(\mathrm{R} \leq 4,000)$.

Figure 2 presents the relative error of the friction factor based on the Swamee \& Swamee equation (2007), which represents an evolution of the Swamee \& Jain formula (1976) and covers the entire $\mathrm{R}$ range and not just the turbulent regime. Therefore, the relative error did not exceed $1 \%$ in the interval corresponding to $\mathrm{R} \leq 4,000$. In the $\mathrm{R}$ range between $8 \times 10^{4}$ and $4 \times 10^{7}$, the relative error exceeded $\pm 0.5 \%$ for certain $\varepsilon / D$ values but did not exceed $\pm 1 \%$. 


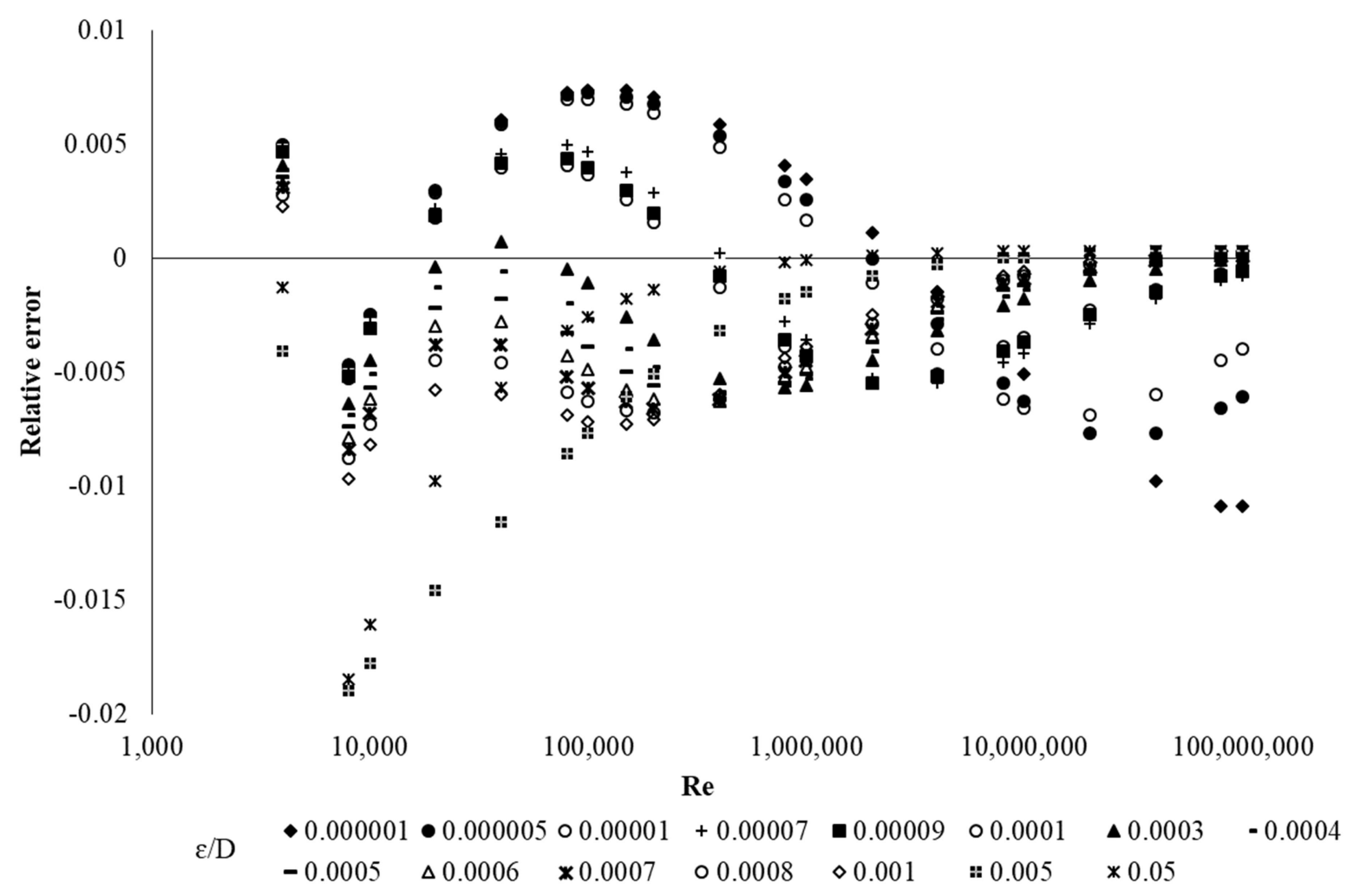

FIGURE 2. Relative error of the Swamee \& Swamee equation (2007) as a function of the Reynolds number.

The performance of the Papaevangelou et al., equation (2010) is shown in Figure 3. The relative error exceeded $\pm 0.5 \%$ for certain $\varepsilon / D$ values in the $\mathrm{R}$ range between 4,000 and 200,000 . However, the relative error did not exceed $\pm 1 \%$ for any $\mathrm{R}$, similar to the findings of Papaevangelou et al., (2010) who proposed the equation.

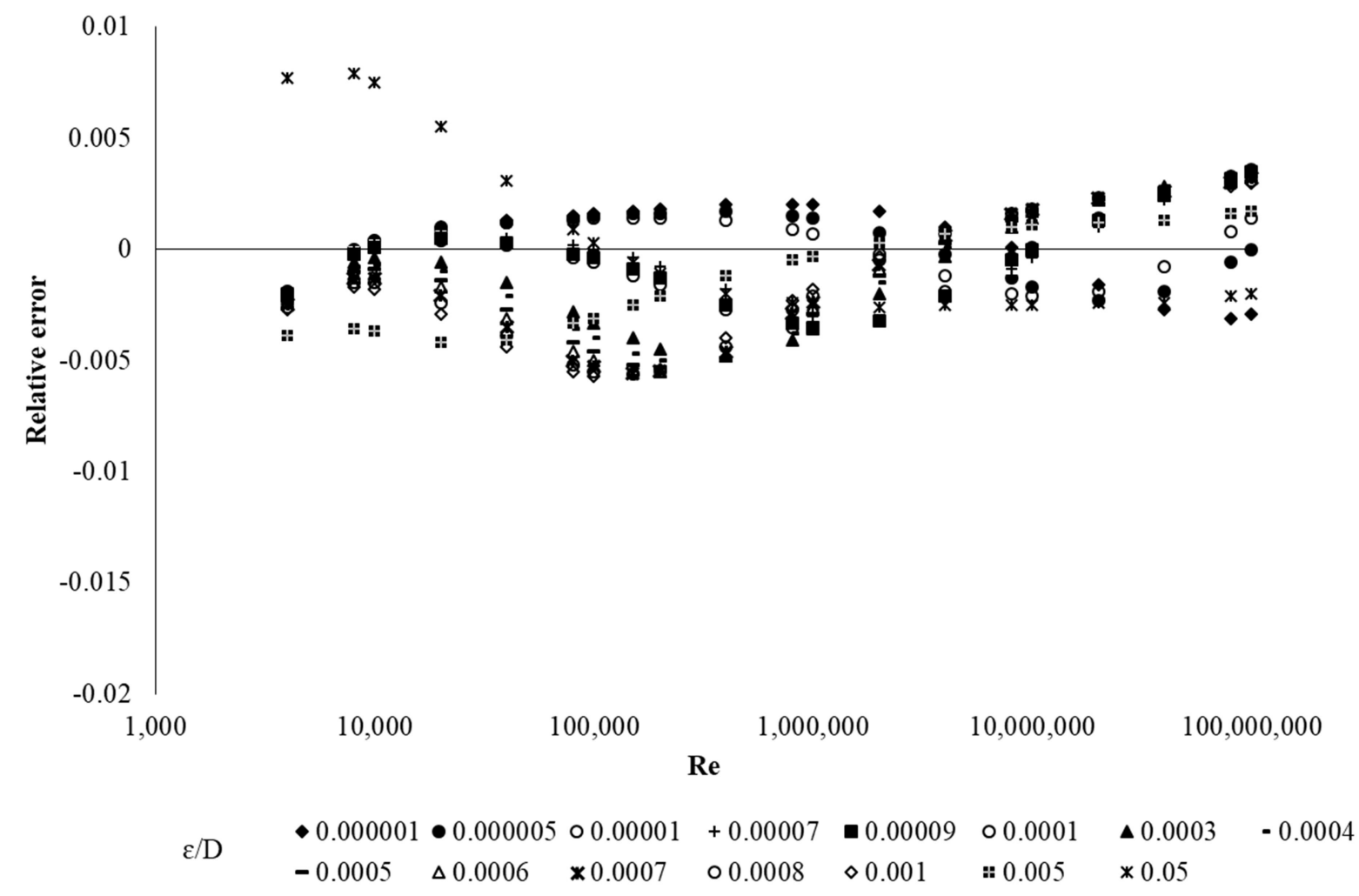

FIGURE 3. Relative error of the Papaevangelou et al., equation (2010) as a function of the Reynolds number. 
The relative error of the Fang et al., (2011) equation did not exceed $\pm 0.5 \%$ for any evaluated interval of $\mathrm{R}$ (Figure 4 ). This equation was ranked as very accurate in the present study and by Offor \& Alabi (2016).

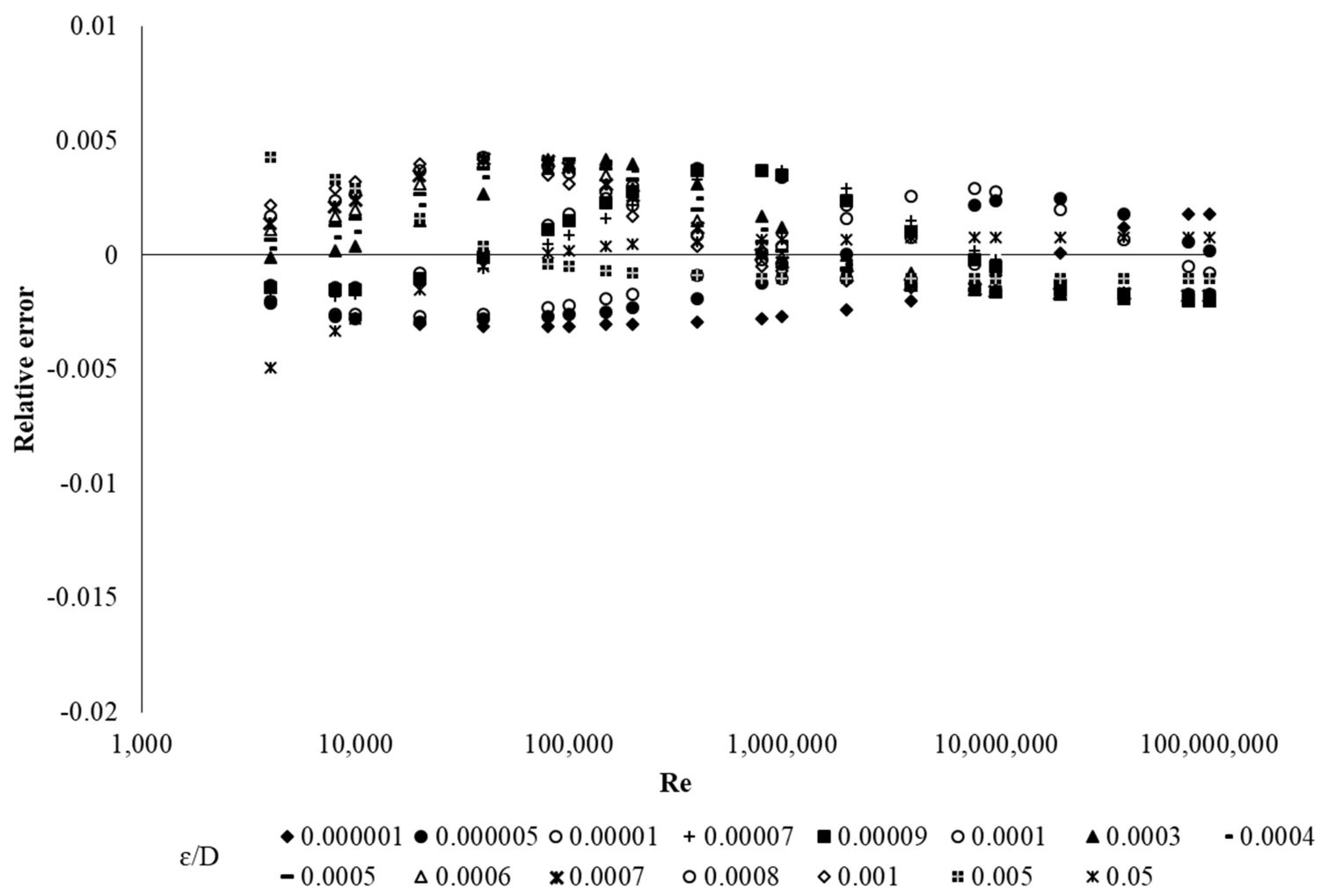

FIGURE 4. Relative error of the Fang et al., equation (2011) as a function of the Reynolds number.

In their study on the computational precision of models used to obtain the friction factor, Offor \& Alabi (2016) proposed an explicit equation and verified that the relative error did not exceed $\pm 0.1 \%$ (Figure 5). In the 320 combinations evaluated in this research, the relative error ranged from $-0.05 \%$ to $0.13 \%$ (Table 4 ). When analyzing a greater number of equations, Pimenta et al. (2018) observed that this equation rendered the best performance in obtaining the friction factor.

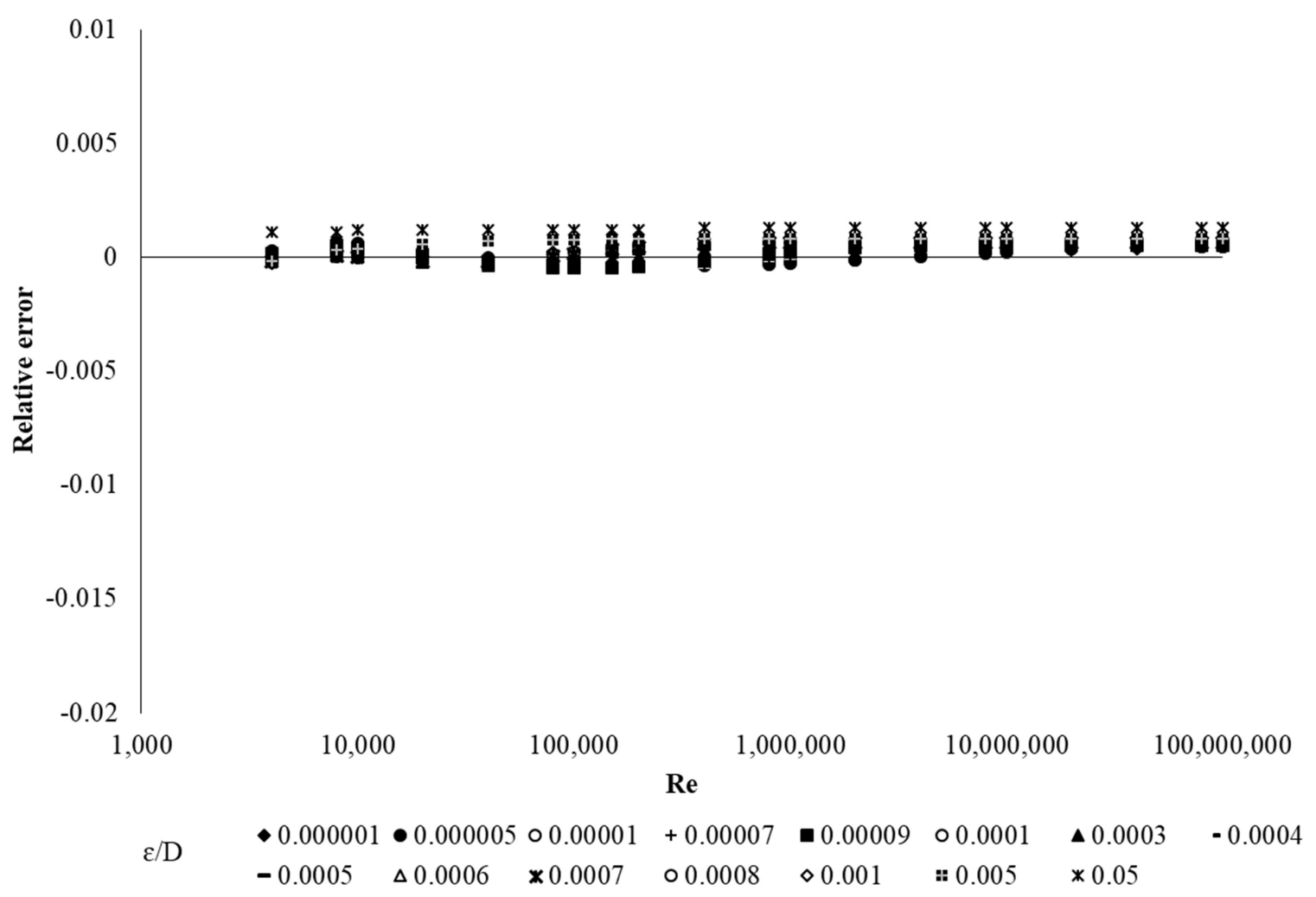

FIGURE 5. Relative error of the Offor \& Alabi equation (2016) as a function of the Reynolds number. 
Using the Vatankhah equation (2018), the relative error for the friction factor ranged from $0.001 \%$ to $0.13 \%$ for any evaluated interval of R (Figure 6), yielding the best performance. Offor \& Alabi (2016) suggested that a good trade-off between accuracy and relative computational efficiency can ensure an ideal explicit equation. The Vatankhah equation (2018) considered both simplicity and accuracy and has been proposed for practical applications.

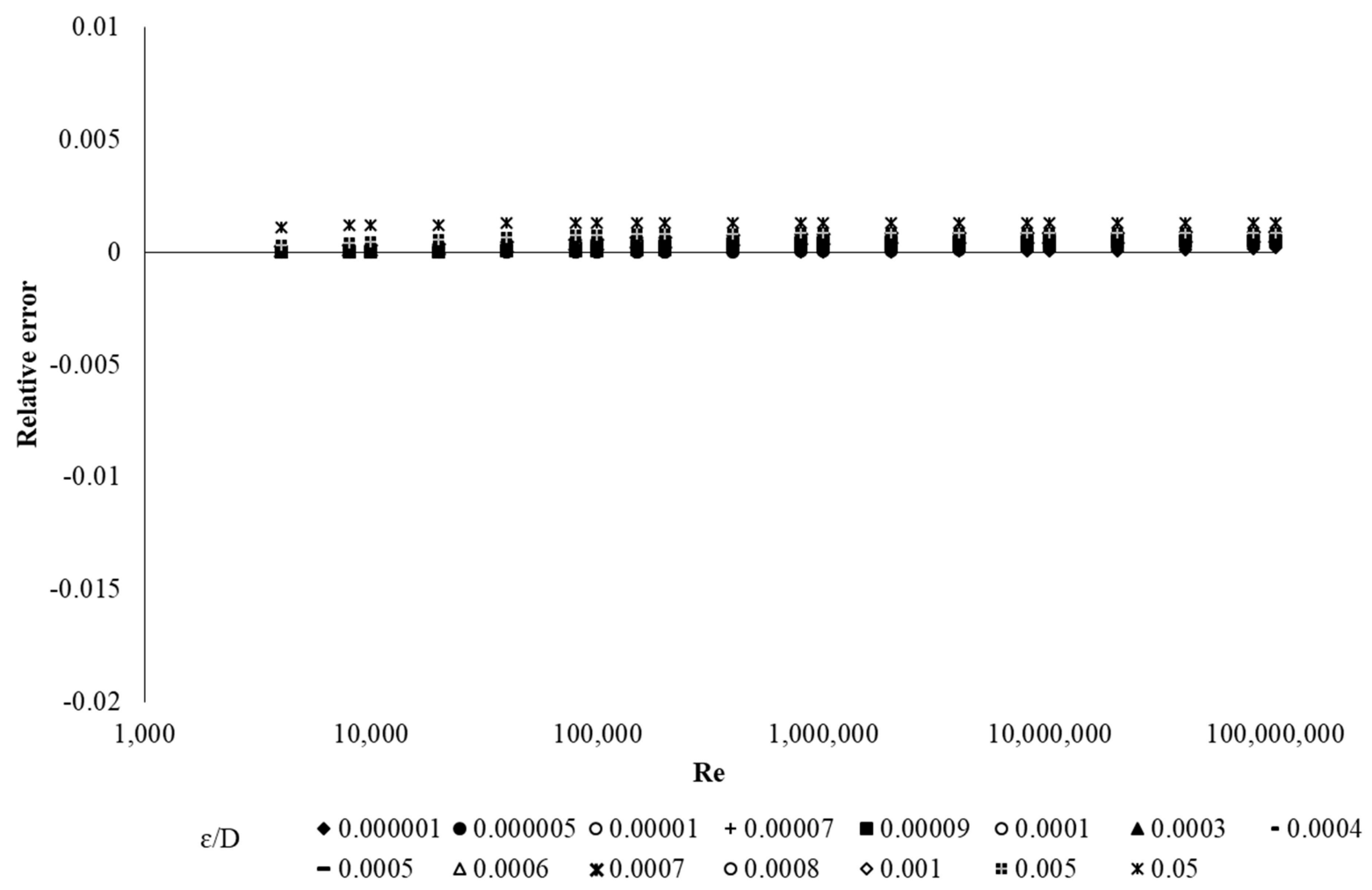

FIGURE 6. Relative error of the Vatankhah equation (2018) as a function of the Reynolds number.

The overall mean values of the relative error and the standard deviation presented in Table 4 show that the best performance over the entire $\mathrm{R}$ range for the evaluated $\varepsilon / D$ ratios was obtained using the Vatankhah equation (2018), followed by the Offor \& Alabi equation (2016), the Fang et al., equation (2011), the Papaevangelou et al., equation (2010), the Swamee \& Swamee equation (2007) and the Swamee \& Jain equation (1976). This performance classification did not change even when the relative error was evaluated separately for the laminar and turbulent regimes (Table 4).

TABLE 4. Mean values, range and standard deviation of the relative error for each equation.

\begin{tabular}{|c|c|c|c|c|c|}
\hline \multirow[b]{2}{*}{ Reference/Equation } & \multirow[b]{2}{*}{$\begin{array}{c}\text { Overall } \\
\text { mean }\end{array}$} & \multicolumn{2}{|c|}{ Mean } & \multirow[b]{2}{*}{ Range } & \multirow[b]{2}{*}{ Standard deviation } \\
\hline & & Laminar regime & $\begin{array}{c}\text { Turbulent } \\
\text { regime }\end{array}$ & & \\
\hline Swamee \& Jain (1976) & 0.00478 & 0.0183 & 0.0041 & -0.0302 to 0.0071 & 0.0044 \\
\hline Swamee \& Swamee (2007) & 0.00385 & 0.0039 & 0.0038 & -0.0190 to 0.0074 & 0.0030 \\
\hline Papaevangelou et al., (2010) & 0.00215 & 0.0026 & 0.0021 & -0.0057 to 0.0079 & 0.0015 \\
\hline Fang et al., (2011) & 0.00184 & 0.0018 & 0.0018 & -0.0049 to 0.0043 & 0.0011 \\
\hline Offor \& Alabi (2016) & 0.00046 & 0.0039 & 0.0005 & -0.0005 to 0.0013 & 0.0003 \\
\hline Vatankhah (2018) & 0.00039 & 0.0001 & 0.0004 & 0.00001 to 0.0013 & 0.0003 \\
\hline
\end{tabular}

In general, the six equations presented an overall mean relative error of less than 0.01 , thereby confirming this study's hypothesis that the implicit Colebrook equation for estimating the friction factor can be replaced with explicit formulas that yield a relative error of less than $1 \%$. The exceptions were the Swamee \& Jain equation (1976), which presented a maximum relative error of -0.0302 - i.e., $-3.02 \%$, and the Swamee \& Swamee equation (2007) with a relative error of $-1.90 \%$.

\section{CONCLUSIONS}

The six explicit formulas, which reduce the complexity of the calculations, presented a relative error in relation to the Colebrook equation of less than $\pm 1 \%$ except for the equations of Swamee \& Jain (1976) and Swamee \& Swamee (2007).

The results show that the explicit equation of this study evolved with the aim of achieving greater accuracy 
and lower calculational complexity. Based on the performance, the Vatankhah equation (2018) is the most highly recommended, followed by the Offor \& Alabi equation (2016), the Fang et al., equation (2011), the Papaevangelou et al., equation (2010), the Swamee \& Swamee equation (2007) and the Swamee \& Jain equation (1976).

\section{ACKNOWLEDGEMENTS}

The authors acknowledge the Coordination for the Improvement of Higher Education Personnel (Capes) for granting a scholarship, the National Council for Scientific and Technological Development (CNPq - 140676/2017-1) for granting a scholarship and the graduate program in Agronomy: Irrigation and Drainage, from the School of Agronomic Sciences (FCA) at UNESP - Botucatu, for providing support.

\section{REFERENCES}

Bardestani S, Givehchi M, Younesi E, Sajjadi S, Shamshirband S, Petkovic D (2017) Predicting turbulent flow friction coefficient using ANFIS technique. Signal, Image and Video Processing 11:341-347.

Brkić D, Ćojbašić Ž (2017) Evolutionary optimization of Colebrook's turbulent flow friction approximations.

Preprints 2(15):1-27.

Churchill SW (1973) Empirical expressions for the shear stressing turbulent flow in commercial pipe. AIChE Journal 19:375-376.

Clamond D (2009) Efficient resolution of the Colebrook equation. Industrial \& Engineering Chemistry Research 48:3665-3671.

Coban MT (2012) Error analysis of non-iterative friction factor formulas relative to Colebrook-White equation for the calculation of pressure drop in pipes. Journal of Naval Science and Engineering 8:1-13.

Colebrook CF (1939) Turbulent flow in pipes, with particular reference to the transition region between the smooth and rough pipe laws. Journal of The Institution of Engineers 11:133-155.

Colebrook CF, White CM (1937) Experiments with fluid friction in roughned pipes. Proceedings of The Royal Society A Mathematical Physical and Engineering Sciences 161(906):367-381.
Fang X, Xu Y, Zhou Z (2011) New correlations of singlephase friction fator for turbulent pipe flow and evaluation of existing single-phase friction fator correlations. Nuclear Engineering and Design 241:897-902.

Haaland SE (1983) Simple and explicit formulas for the friction factor in turbulent pipe flow. Journal of Fluids Engineering 105:89-90.

Mikata Y, Walczak WS (2016) Exact Analytical Solutions of the Colebrook-White Equation. Journal of Hydraulic Engineering 142(2):04015050.

Moody LF (1944) Friction factors for pipe flow. Transactions ASME 66:671-678.

Moody LF (1947) An approximate formula for pipe friction factors. Transactions ASME 69:1005-1006.

Offor UH, Alabi SB (2016) An Accurate and Computationally Efficient Explicit Friction Factor Model. Advances in Chemical Engineering and Science 6:237-245.

Papaevangelou G, Evangelides C, Tzimopoulos C (2010) A new explicit equation for the friction coeficiente in the Darcy-Weisbach equation. Proceedings of the Tenth Conference on Protection and Restoration of the Environment 166:6-9.

Pimenta BD, Robaina AD, Peiter MX, Mezzomo W, Kirchner JH, Ben LHB (2018) Performance of explicit approximations of the coefficient of head loss for pressurized conduits. Revista Brasileira de Engenharia Agrícola e Ambiental 22(5):301-307.

Rocha HS, Marques PAA, Camargo AP, Frizzone JA, Saretta E (2017) "Internal surface roughness of plastic pipes for irrigation. Revista Brasileira de Engenharia Agrícola e Ambiental 21:143-149.

Swamee PK, Jain AK (1976) Explicit equations for pipe flow problems. Journal of Hydraulics Division 102:657-664.

Swamee PK, Swamee N (2007) Full-range pipe-flow equations. Journal of Hydraulic Research 45:841-843.

Testezlaf R (1982) Estudo de perda de carga em tubulações e engates rápidos utilizados em linhas de irrigação. Master's Thesis, Campinas, Universidade Estadual de Campinas.

Vatankhah AR (2018) Approximate analytical solutions for the colebrook equation. Journal of Hydraulic Engeneering 144(5). DOI: https://doi.org/10.1061/(ASCE)HY.1943-7900.0001454 